\title{
Perception of Foot Temperature in Young Women with Cold Constitution: Analysis of Skin Temperature and Warm and Cold Sensation Thresholds
}

\author{
Mieko Sadakata $^{1)}$ and Yoshiaki Yamada ${ }^{2)}$ \\ 1) School of Health Sciences Faculty of Medicine Niigata University \\ 2) Niigata University Graduate School of Medical and Dental Sciences
}

\begin{abstract}
To examine the disease state of cold constitution, physiological measurements of the foot were conducted by investigating thermal sensations under an environmental condition of $25^{\circ} \mathrm{C}-26^{\circ} \mathrm{C}$ (neutral temperature) in 29 young women with and without cold constitution. The subjects were classified into 3 groups according to their experiences with cold constitution: cold constitution, intermediate, and normal groups. Foot skin temperature was measured by thermography. Thermal sensations were measured on the dorsum of the left foot using a thermal stimulator. Cold and warm spots on the dorsum of the right foot were ascertained. Thermal stimulation was delivered by a copper probe. No significant differences in foot skin temperature among these 3 groups were identified as measured in a laboratory under neutral temperature conditions. However, the mean warm sensation threshold was $+6.3 \pm 1.09^{\circ} \mathrm{C}$ (mean $\pm \mathrm{SEM}$ ) for the cold constitution group $(\mathrm{n}=14),+3.4 \pm 2.10^{\circ} \mathrm{C}($ mean \pm SEM) for the intermediate group $(n=7)$, and $-0.25 \pm 1.96^{\circ} \mathrm{C}$ (mean \pm SEM) for the normal group $(n=6)$. The difference was significant between the cold constitution and normal groups. No significant differences among the 3 groups were found in the cold sensation threshold. This may be attributable to the distribution of thermal receptors and to chronically reduced blood flow in subcutaneous tissues, where the skin temperature receptors responsible for temperature sensation are located. J Physiol Anthropol 26(4): 449-457, 2007 http://www.jstage.jst.go.jp/browse/jpa2

[DOI: 10.2114/jpa2.26.449]
\end{abstract}

Keywords: cold constitution; young women; temperature sensation; warm sensation threshold; cold sensation threshold; skin temperature

\section{Introduction}

Cold constitution uniquely affects women, but is often overlooked medically and is not objectively understood. Cold constitution in women was first examined in 1956 (Kushima,
1956), but there have been few investigations of this phenomenon over the last 5 decades. When establishing treatments and countermeasures for cold constitution, the subjective features of the condition must first be objectively assessed. No general consensus has been reached, however, on the definition of cold constitution (Takeya, 2003); nor are assessment standards currently available.

Some studies on cold constitution have focused on phenomena occurring on the skin surface caused by regulation of peripheral body temperature (Matsumoto, 1990; Horikawa, 1993; Watanabe, 1997; Arakawa, 1999). Thermography showed reduced vascular responses to cold temperatures and large differences in skin temperature between the abdomen and dorsum of the foot (Takatori, 1992). An electrocardiographic study showed that the QT time and R-R interval in persons with cold constitution tended to be longer, and the heart rate was significantly lower than in those without cold constitution (Aomine and Yamato, 2002). In addition, persons with cold constitution had accelerated skin vasoconstriction during exposure to cold temperatures and hypometabolism (Hosono, 2003). Functional MRI has shown a relationship between cold constitution and the amygdaloid nucleus (Hosono, 2003). Thus, studies are being conducted to objectively ascertain the mechanisms of cold constitution as well as its symptoms.

The present study concentrated on cold constitution and temperature sensation. In general, changes of in vivo body temperatures are transmitted from temperature receptors to the thermoregulatory center within the central nervous system. Temperature receptors are widely distributed within the peripheral and central nervous systems and temperature information is integrated in the central nervous system to regulate body temperature. Temperature information for controlling body temperature is transmitted through sensations that can be felt or expressed as "coldness" and "warmness". Behavioral body temperature regulation is performed based on these sensations. We consider that the perception of cold in persons with cold constitution results from integration of temperature sensations such as "coldness" and "warmness," thermal sensations, and thermal comfort and discomfort. 
Table 1 Physical Characteristics of the subjects

\begin{tabular}{lcccr}
\hline & $\begin{array}{c}\text { Cold constitution } \\
\text { group } \\
(\mathrm{n}=14)\end{array}$ & $\begin{array}{c}\text { Intermediate } \\
\text { group } \\
(\mathrm{n}=8)\end{array}$ & $\begin{array}{c}\text { Normal group } \\
(\mathrm{n}=7)\end{array}$ & \multicolumn{1}{c}{ All subjects } \\
& $(\mathrm{n}=29)$ \\
\hline Age & $22.4 \pm 3.03$ & $21.5 \pm 1.20$ & $20.7 \pm 0.49$ & $21.8 \pm 2.28$ \\
Height $(\mathrm{cm})$ & $159.3 \pm 4.38$ & $157.6 \pm 4.41$ & $162.4 \pm 4.86$ & $159.6 \pm 4.69$ \\
Weight $(\mathrm{Kg})$ & $51.1 \pm 5.59$ & $52.9 \pm 4.51$ & $56.9 \pm 6.76$ & $53.0 \pm 5.91$ \\
BMI & $20.1 \pm 1.53$ & $21.3 \pm 1.34$ & $21.6 \pm 2.46$ & $20.8 \pm 1.82$ \\
Body fat rate $(\%)$ & $25.1 \pm 3.94$ & $26.5 \pm 3.61$ & $25.7 \pm 4.61$ & $25.6 \pm 3.93$ \\
Temperature $\left({ }^{\circ} \mathrm{C}\right)$ & $36.7 \pm 0.36$ & $36.8 \pm 0.33$ & $36.5 \pm 0.26$ & $36.7 \pm 0.33$ \\
Pulse $(/ \mathrm{min})$ & $67.2 \pm 10.5$ & $68.0 \pm 6.78$ & $61.1 \pm 7.56$ & $65.5 \pm 9.03$ \\
\hline
\end{tabular}

Note) Values are means \pm SD. BMI: Body Mass Index $=$ Weight $(\mathrm{Kg}) /\{\text { Height }(\mathrm{m})\}^{2}$.

Persons with cold constitution experience feelings of severe cold at low temperatures. Knowing how these individuals perceive ambient temperatures may help to clarify the symptoms of cold constitution. To objectively examine the disease state in cold constitution, we investigated thermal sensations in individuals with cold constitution by ascertaining warm and cold spots in the foot, which are static thermal sensors involved in thermal sensation input, and by measuring thermal sensation thresholds in the foot, which are dynamic thermal sensation parameters.

\section{Methods}

\section{Experimental conditions}

Measurements were performed in a climate-controlled chamber at $25.0-26.0^{\circ} \mathrm{C}$ (neutral temperature), relative humidity of $50 \pm 5 \%$, and air movement of $0.1 \mathrm{~m} / \mathrm{s}$. The study was conducted in May and June of 2004. The outdoor environmental temperature was $24.5 \pm 3.03^{\circ} \mathrm{C}$ (mean $\pm \mathrm{SD}$ ) during the experimental period. According to measurement standards established by The Japanese Society of Thermology (1999), subjects refrained from eating 2 hours, smoking 4 hours, and exercising 1 day before the measurement. The subjects slept more than 7 hours before the test, and were dressed in a short-sleeved shirt and shorts based on 0.45 clo units in accordance with the laboratory room temperature $\left(25^{\circ} \mathrm{C}\right)$, airflow $(=0.1 \mathrm{~m} / \mathrm{s})$ and work intensity (at rest). The subject sat quietly on a chair for $5 \mathrm{~min}$ before the start of any of the studies. (Semi-Fowler's position $\left(45^{\circ}\right)$ ).

\section{Subjects and operational definition of cold constitution}

Twenty-nine healthy young women in their twenties participated in the experiment, which was approved by the Ethical Review Board of Niigata University Dental Faculty. The purposes of the study and the procedures related to their participation were explained to the subjects. The subjects were also provided with a written document containing this information. Subjects who agreed to participate signed a consent form. The physical characteristics of the subjects are summarized in Table 1.

The operational definition of cold constitution in the present study was: "Exposure to a cold environment causes coldness of the periphery of the extremities and trunk. A case history includes accompanying symptoms and pain in cold environments. Symptoms often persist for long period of time." Although a definition of cold constitution has not yet been established, the above-mentioned operational definition was based on hypothetical definitions in previous major studies (Kushima, 1956; Nanzandoh, 2002; Terasawa, 1987; Ishino, 1990; Takatori, 1990).

Based on the operational definition, subjects were divided into 3 groups (cold constitution, intermediate, and normal) with respect to the following 4 items, shown on Table 2:1) subjective cold constitution; 2) pain upon feeling cold; 3) accompanying symptoms; and 4) a history of cold constitution of $>1$ year. Criteria for classification of subjects are shown in Table 3.

\section{Measurement procedures}

Figure 1 shows the measurement procedures. The skin temperature of the foot was measured by thermography every 5 min for $50 \mathrm{~min}$, as were subjective thermal sensations. After defining the left and right dorsum of the foot by drawing a line from the ankle (a line connecting the lateral and medial malleoli) to the tip of the toes, the skin surface temperature was measured.

Warm and cold sensation thresholds were measured on the dorsum of the left foot using a thermal stimulator of $0.9 \times 0.9$ $\mathrm{cm}$ at the tip by the Method of Limits. Thresholds were measured after confirming that the skin temperature at the dorsum of the left foot ranged from $31-34^{\circ} \mathrm{C}$ (Fruhstorfer, 1976; Tazaki and Ogawa, 1989). Temperature of the thermal stimulator was measured from $31-34^{\circ} \mathrm{C}$. Hot water and cold water were used to change the temperature of the thermal stimulator within a range of $15-45^{\circ} \mathrm{C}$ at a rate of $1.6^{\circ} \mathrm{C} / \mathrm{s}$. When the subjects reported thermal sensation of warmness or coldness, temperature changes were recorded as thermal sensation. Measurements were repeated 4 times in each experiment. Due to the risk of scalding, the highest temperature applied was $45^{\circ} \mathrm{C}$, this having been approved by the ethical review board.

Cold and warm spots were measured on the dorsum of the 
Table 2 Survey on subjective symptoms of cold constitution

1. Do you sometimes feel cold? Please circle only one answer.

a. I never feel cold. b. Sometimes I feel a little cold. c. I feel more than a little cold but not often.

d. I often feel cold. e. I always feel cold. f. Others

2. If you circled "b," "c," "d," or "e" to question 1, could you tell what way you feel cold?

a. It is not painful when I feel cold. b. It is a little painful and uncomfortable when it cools down.

c. It is painful when it cools down. d. When it cools down, it is very painful.

3. If you circled "b" "c" "d" "e" in question 1: When it is cold I feel other symptoms not limited to the part of the body that feels cold? Please circle only one answer.

a. yes b. no.

4. If you circled "b," "c," "d," or "e" to question 1, how long you have had such feelings about cold? Please circle only one answer.

a. From the time I was a schoolchild. b. From the time I was a junior high school student.

c. From the time I was a senior high school student. d. After high school graduation.

e. I do not remember.

f. Others $(\quad)$

Note) We based assigning subjects into 3 groups on answers to these questions.

Table 3 Criteria for classifications of subjects

\footnotetext{
Cold constitution group: satisfied all 4 items:

1) Subjective cold constitution (No. 1: selected either b, c, d, or e).

2) Past history of pain (No. 2: selected b, c, or d).

3) Accompanying symptoms (No. 3: a. yes).

4) History of cold constitution $>1$ year based on mean age of subjects. (No. 4 selected either a, b, c, or d.)
}

Intermediate group: satisfied

1) Awareness of cold and either

2) Past history of pain or 3) Accompanying symptoms.

Normal grup: satisfied none of these criteria.

right foot. Using a $2 \times 2 \mathrm{~cm}$ rubber stamp (100 segments of $2 \times 2 \mathrm{~mm}$ ), a grid was marked on the dorsum of the right foot, and warm and cold spots were counted in the 100 segments. Thermal stimuli were delivered by a copper probe. The temperature of the copper probe was set at 15 and $45^{\circ} \mathrm{C}$ (Physiological Society of Japan 2001). The interval of stimulation was set at $2 \mathrm{~s}$, with an interval of a few minutes between each measurement.

\section{Data analysis}

Skin temperature

Thermal image processing software (TH-51-701, $1.1 \mathrm{~A}(\mathrm{~J})$; NEC San-ei, Japan) was used to calculate the mean, minimal, maximum, and standard deviation of temperature distribution in each region. Data were collected 8 times $(0,20,25,30,35$, 40,45 , and $50 \mathrm{~min}$ after the start of adaptation) for each region. Temperature sensation threshold

Differences between skin temperature and declared warm sensation were calculated using the following formula: "skin temperature-warm sensation threshold.” Differences between skin temperature and declared cold sensation were calculated by using the following formula: "skin temperature-cold sensation threshold." The mean of 4 measurements was calculated.

\section{Statistical analysis}

Statistical analysis was performed using SPSS Statistical Software (10.1 J, Advanced Models). Statistically significant intergroup differences were determined by one-way ANOVA. A statistically significant difference was accepted at $p<0.05$.

\section{Results}

\section{Skin temperature}

Figure 2 shows the mean skin temperatures of the three groups. At the time of the start of adaptation, skin temperature tended to be higher for the cold constitution group than for the intermediate and normal groups, but differences were not significant among the three groups. From 20-50 min, the foot skin temperature for the cold constitution group was lower than for the other groups, but no significant differences among the three groups were found.

\section{Temperature sensation}

1) Declared thermal sensation temperature

Figure 3 shows the temperatures at which the 3 groups declared warmth and cold, respectively. The temperatures at which warmth was felt were $39.2 \pm 0.96^{\circ} \mathrm{C}$ (mean \pm SEM) for the cold constitution group $(n=14), \quad 35.9 \pm 2.09^{\circ} \mathrm{C}$ (mean \pm SEM) for the intermediate group $(n=7)$, and $32.9 \pm 1.88^{\circ} \mathrm{C}($ mean \pm SEM) for the normal group $(n=6)$. A significant difference was observed between the cold constitution and normal groups $(p=0.022$, ANOVA, Bonferroni). Temperatures at which cold was felt were $25.0 \pm 1.04^{\circ} \mathrm{C}$ (mean $\left.\pm \mathrm{SEM}\right)$ for the cold constitution group $(\mathrm{n}=14), 23.6 \pm 1.91^{\circ} \mathrm{C} \quad($ mean $\pm S E M)$ for the intermediate group $(n=7)$, and $26.4 \pm 1.83^{\circ} \mathrm{C}($ mean $\pm S E M)$ for the normal group $(n=6)$. No significant differences among the three groups were found.

2) Skin temperature-temperature sensation threshold (relative value)

Results of studies of the warm sensation threshold (skin temperature-warm sensation threshold) are shown in Fig. 4. 
Entering laboratory

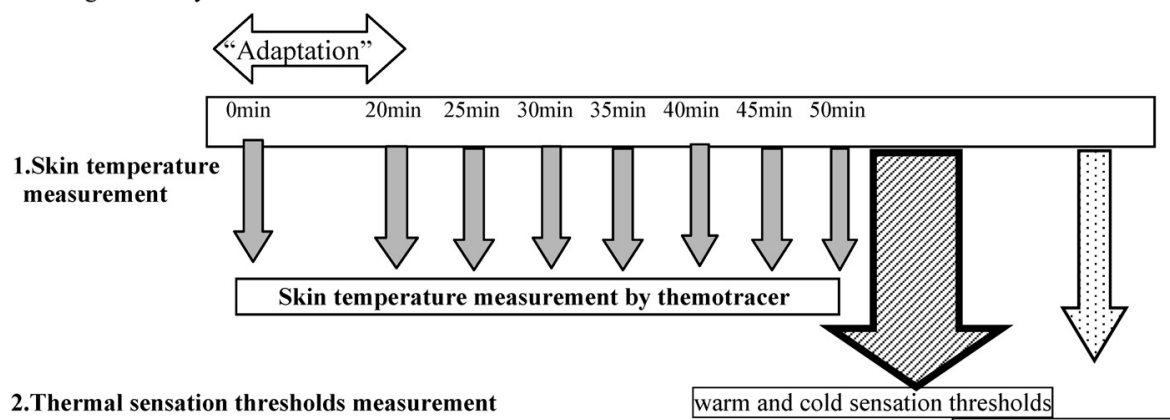

Warm spots and cold spots

Fig. 1 Measurement procedures.

Skin temperature was measured by a Thermotraser. Using the method of limits, temperature sensation thresholds were measured alternatively from low to high.

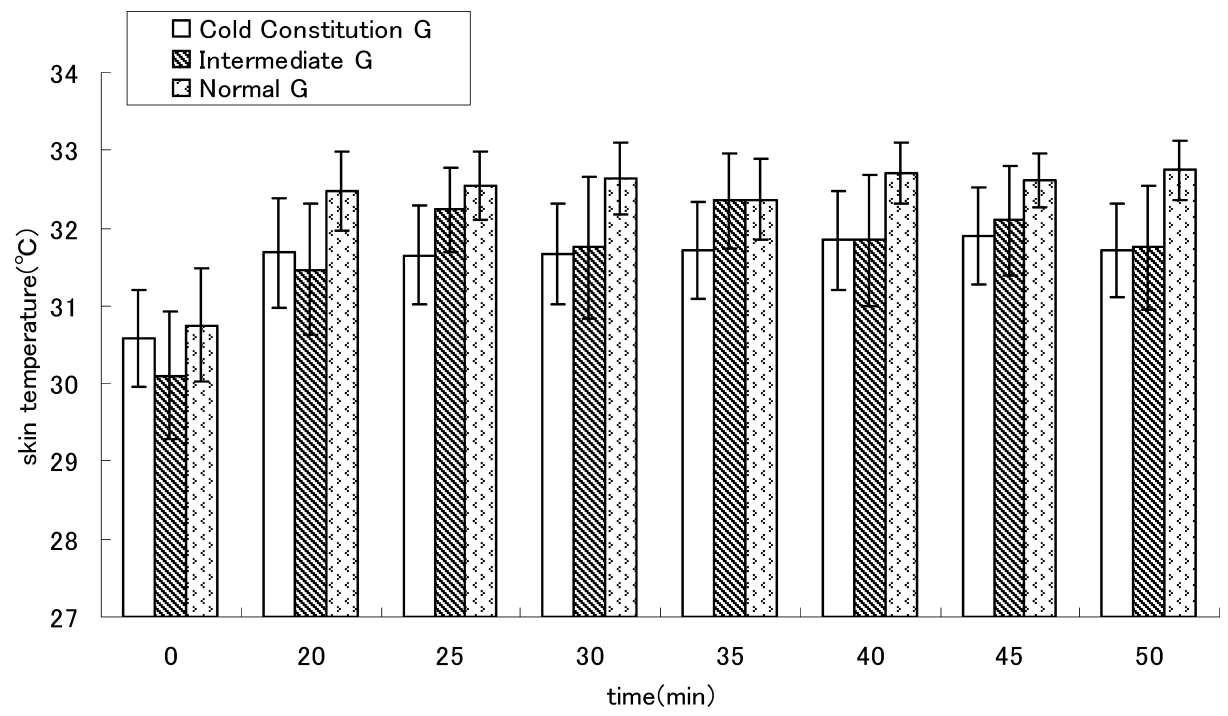

Fig. 2 Skin temperature was measured on the left foot where temperature sensation thresholds were also measured. Y axis shows mean values. ANOVA showed no significant difference among the three groups although after the 20-min. period of adaptation, the foot skin temperature tended to be lower in the cold constitution group.

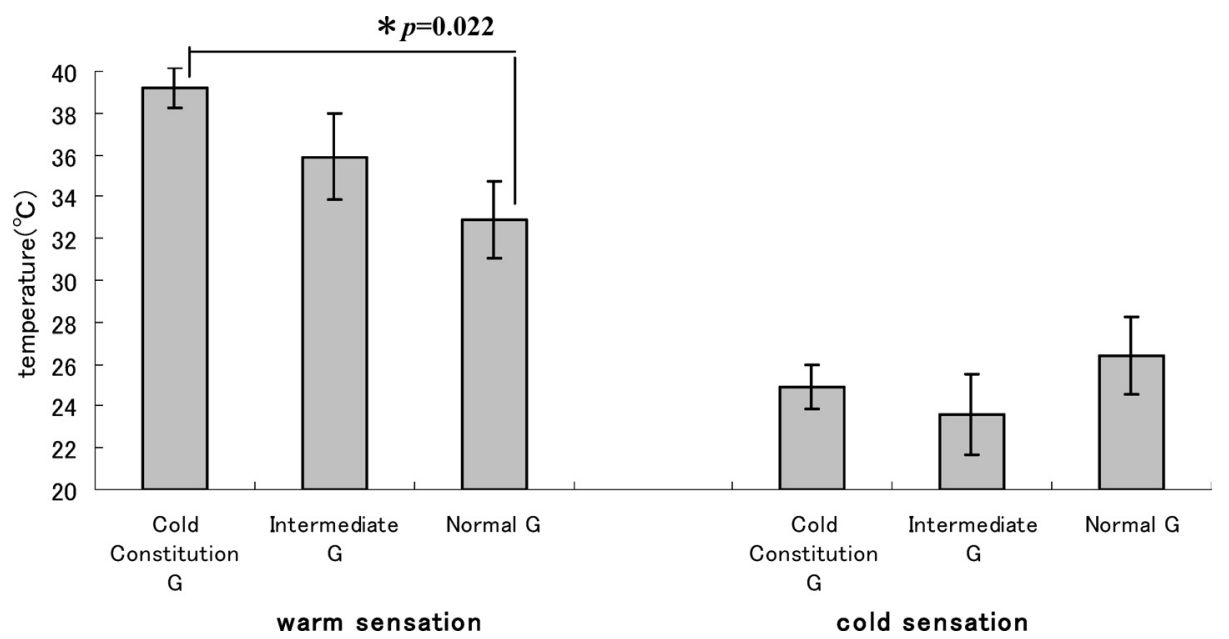

Fig. 3 Declared warm sensation temperature was defined as the temperature at which the subject felt warmth and the declared cold sensation temperature was defined as the temperature at which the subject felt coldness. Declared warm and cold sensation temperatures were each measured 4 times in each subject and averaged. Values are means for groups. ${ }^{*} p<0.05$ indicates a significant main effect (thermal sensation) as determined by ANOVA. 


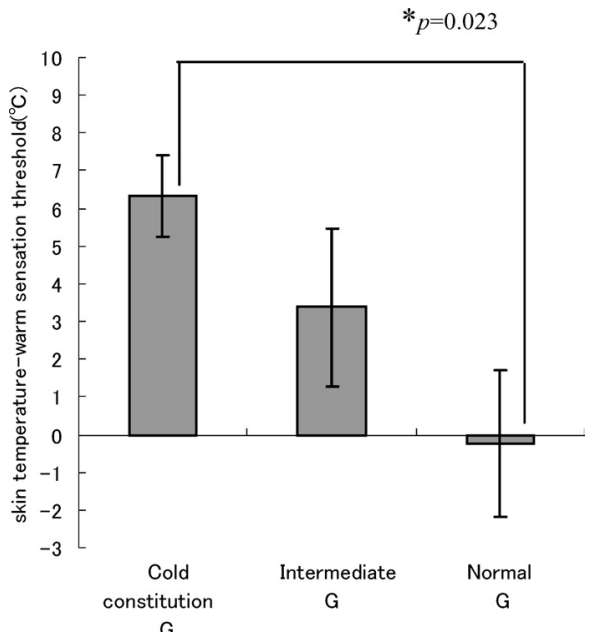

Fig. 4 As dynamic temperature sensations are based on skin temperature, differences between skin temperature and the declared warm temperature were calculated. The difference between skin temperature and declared warm sensation was calculated using the following formula: "skin temperature-warm sensation threshold". Declared warm sensation temperatures were measured a total of 4 times in each subject and averaged. Values are means for groups. $* p<0.05$ indicates a significant main effect (thermal sensation) as determined by ANOVA.

The warm sensation thresholds were $+6.3 \pm 1.09^{\circ} \mathrm{C}$ (mean \pm SEM) for the cold constitution group $(n=14)$, $+3.4 \pm 2.10^{\circ} \mathrm{C}$ (mean $\pm \mathrm{SEM}$ ) for the intermediate group $(\mathrm{n}=7)$, and $-0.25 \pm 1.96^{\circ} \mathrm{C}($ mean \pm SEM $)$ for the normal group $(\mathrm{n}=6)$. A significant difference was noted between the cold constitution and normal groups $(p=0.023$, ANOVA, Bonferroni). In the normal group, the subjects reported warmth at temperatures near the initial skin temperature. On the other hand, in the cold constitution group, subjects reported warmth when the skin temperatures increased $6^{\circ} \mathrm{C}$ from the initial value.

The cold sensation threshold (skin temperature-cold sensation threshold) was $-7.8 \pm 1.02^{\circ} \mathrm{C}$ (mean \pm SEM) for the cold constitution group $(\mathrm{n}=14)$ and $-6.8 \pm 1.74^{\circ} \mathrm{C}$ (mean \pm SEM) for the normal group $(n=7)$ (Fig. 5). The cold sensation threshold for the intermediate group $(n=6)$ was $-8.9 \pm 1.59^{\circ} \mathrm{C}($ mean $\pm \mathrm{SEM})$. Although the cold sensation threshold of the intermediate group was lower than that of the cold constitution group, differences were not significant among groups.

3) Number of cold and warm spots

Cold and warm spots were counted in 28 subjects, but due to crowding of the spots, consecutive warm and cold spots were noted along 10 segments in some subjects. As a result, 5 measurements were redone. Even after retesting, many consecutive warm and cold spots were found in 4 measurements; therefore, these results were removed from analysis. Subsequently, 26 cold-spot and 24 warm-spot measurements were analyzed, with the results shown in Fig. 6. No significant difference in the number of cold and warm spots

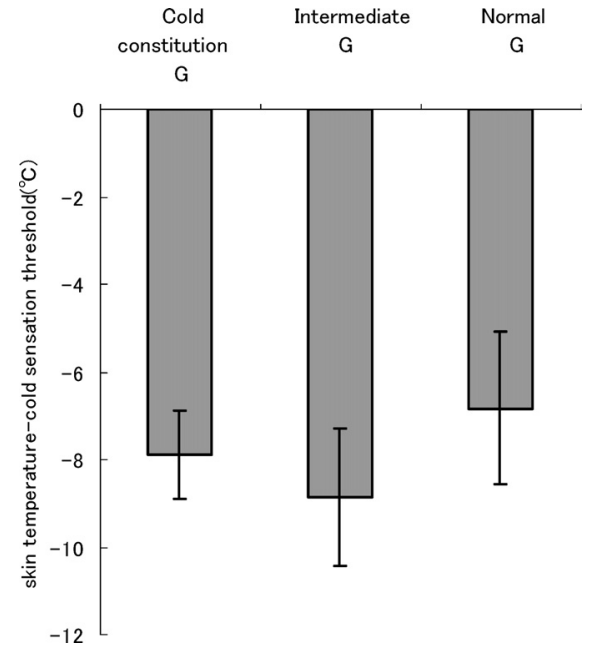

Fig. 5 As dynamic temperature sensations are based on skin temperature, the difference between skin temperature and declared cold temperatures was calculated. Differences between skin temperature and declared cold sensation were calculated using the following formula: "skin temperature-cold sensation threshold". Declared cold sensation temperatures were measured 4 times in each subject, and averaged. Values are means for groups. There was no significant difference between three groups.

was noted among the three groups because the standard deviation was large in each group due to individual differences.

\section{Discussion}

\section{Skin temperature in a neutral temperature environment}

With regard to skin temperature measurements, in a discussion of the relationship of ambient and skin temperatures, it was determined that a comfortable temperature was $27^{\circ} \mathrm{C}$, and that at this temperature the mean foot skin temperature was $30.5 \pm 0.2^{\circ} \mathrm{C}$. (Webb, 1922). Results were thus comparable to the present study that measured foot skin temperature at a neutral temperature of $25-26^{\circ} \mathrm{C}$. Nagashima (2002) examined the relationship between skin and ambient temperatures in women with and without cold constitution at two environmental temperatures of $23.5^{\circ} \mathrm{C}$ and $29.5^{\circ} \mathrm{C}$. No differences in both core and skin temperatures were found between women with and without cold constitution at $29.5^{\circ} \mathrm{C}$, and no significant differences in skin temperatures were noted at $23.5^{\circ} \mathrm{C}$.

In the present study, no significant decrease over time in foot skin temperature was seen for the cold constitution group. In this experiment, the outside air temperature was comparable to the mild-cold exposure environment of $23.5^{\circ} \mathrm{C}$ in the Nagashima study. The outside air temperature of around $24.5^{\circ} \mathrm{C}$ and indoor temperatures of $25-26^{\circ} \mathrm{C}$ in the present study and indoor temperatures of around $23.5^{\circ} \mathrm{C}$ in Nagashima's study did not lower foot skin temperature in any subjects, including those in the cold constitution group. In a season when the difference between outside and laboratory 


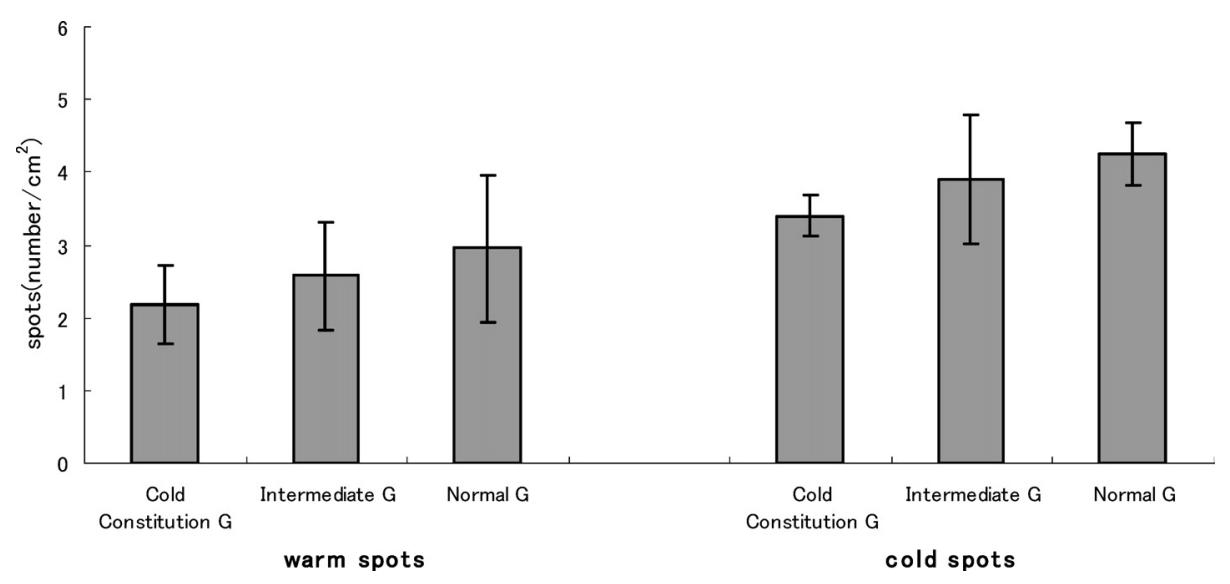

Fig. 6 The number of cold and warm spots per 100 segments was counted, and the density of cold and warm spots was expressed as spots per square centimeter. Values are means for groups. No significant difference was found between the 3 groups.

temperatures is minimal, individuals with cold constitution did not experience cold-resistance reactions severe enough to lower foot skin temperature. As a result, peripheral skin temperatures were not lowered in the present study.

\section{Characteristics of temperature sensation}

The warm temperature threshold was minus in the normal group, because some subjects reported a warm sensation even though the skin temperature was lower than the initial skin temperature. The mean initial skin temperature was $32.9^{\circ} \mathrm{C}$ in the cold constitution group, $32.5^{\circ} \mathrm{C}$ in the intermediate group, and $33.2^{\circ} \mathrm{C}$ in the normal group. Thus, we measured the warm temperature threshold in the dorsum of the right foot at temperatures ranging from $31^{\circ} \mathrm{C}-34^{\circ} \mathrm{C}$. By stabilizing the speed of the temperature change and the size of the area of stimulation, we were able to measure temperature sensations under conditions whereby there were no differences in initial skin temperature. However, the normal group was sensitive to warmth and reported a warm sensation at a temperature close to skin temperature. The difference in the warm sensation threshold of the intermediate group compared to that of the normal group was small. The cold constitution group reported a warm sensation at $+6.3^{\circ} \mathrm{C}-1.09^{\circ} \mathrm{C}$ above the initial skin temperature. However, no significant differences among the 3 groups in the cold sensation threshold were noted.

On the other hand, as for "warm spots" and "cold spots," there was not a significant difference among the three groups. From these results we can say that in the cold constitution group, the warm sensation threshold was higher than in the other two groups, but the cold sensation threshold did not differ among groups. Thus, temperature sensation was static in the warm spots. Temperature sensation is caused by information on temperature from peripheral thermorecepters, which is then received by the somatosensory area of the brain via the spinal cord. As with involvement of the central nervous system and the integration of temperature information, there may be many factors that influence the warm sensation in the central path of warm and cold sensations (Iriki, 2003).
However, we do not have exact knowledge of those mechanisms; we know only that peripheral thermoreceptors react to temperature information from skin temperature and hypoderm temperature. Therefore, we examined factors related to the input of temperature information from the external environment.

At the beginning of the study, we hypothesized that women with cold constitution would display hyper- or hyposensitivity to cold stimulation, but no significant differences among the three groups in the cold sensation threshold were noted. No studies of cold constitution have yet been conducted in Western countries; thus, its incidence is not known. Even in Japan, no studies have focused on cold constitution and temperature sensation. For this reason, the results on the warm sensation threshold of persons with cold constitution cannot be compared with those of previous studies. While direct comparison is therefore not possible, we examined results of investigations on the effects of age and gender on warm and cold sensation thresholds that used an instrument to measure dynamic temperature sensations.

Stevens and Choo (1998) reported that the sensation of warmth gradually dulled with aging, particularly in the peripheral areas of the body, and that reduced peripheral circulation might chronically affect sensations of warmth. Harju (2002), in investigating the relationship of cold and warm sensations to age, gender, and body part, found individual differences in the perception of cold and warm stimulation. However, there were no differences according to age in warm and cold sensation thresholds as assessed by dynamic temperature sensation testing. Harju (2002) suggested that methods of measurement of thermal thresholds be standardized to verify changes in thermal sensation thresholds due to aging. Ohnishi et al. (1992) measured discrimination thresholds of cold and warm sensations in healthy individuals and documented increases in the warm sensation threshold with aging. Iriki (2003) described decreases in temperature perception in the elderly as due to the effects of aging on the input system of the thermoregulatory center. Thus, results of 
these studies suggest that temperature sensitivity becomes lower due to aging, but in the present study no age differences existed among the groups. As for studies on cold constitution, Takatori et al. (1990) found that skin temperatures at the palm and foot were low in a neutral temperature environment. They speculated the cause to be contraction of peripheral arteriovenous anastomoses due to excitation of the vascular motor center at the spinal level. Matsumoto (2001) also reported low skin temperatures in the peripheral regions in the foot, and relevance of cutaneous blood flow to cold constitution was shown through that study.

In the present study, no significant differences among the three groups were found in the cold sensation threshold, while the warm sensation threshold for the cold constitution group was significantly higher than in the other groups. Warm and cold sensations are transmitted via small-diameter myelinated fibers or unmyelinated $\mathrm{C}$ fibers, respectively. According to Ohnishi (1992), warm and cold thresholds increased with aging. Sugiyama (1993) conducted a clinical physiological study on abnormal thermal sensations in order to clarify its mechanisms through an ischemic block method using a cuff. There was no significant difference in the warm sensation threshold with and without the ischemic block, but the ischemic block induced a larger cold sensation threshold. (Sugiyama, 1993).

In the study reported here, skin temperature, which is reflected by the level of blood flow, did not differ significantly among the three groups, although the skin temperature in the cold constitution group was slightly lower in the left foot in comparison with the other two groups. However, the results of measurement in the laboratory in a neutral temperature environment in winter showed a significant decline in skin temperature and skin blood flow in the cold constitution group (Sadakata, 2003; 2004). Tsunoda (2005) noticed a decline in the reaction of somatic receptors by cooling, and examined sensation on the sole of the foot after soaking the foot in hot water. He reported a rise in sensitivity and cognitive function of sensory receptors in the foot by warming. Because the cold constitution group is influenced by environmental temperature and, consequently, the decline in skin temperature and skin blood flow in limbus's ends are apparent, we must study skin blood flow in relation to the warm sensation and examine the involvement of the decline of skin temperature in relation to peripheral circulation.

How does one explain the finding that although no significant differences among the three groups were shown in the cold sensation threshold, the warm sensation threshold in the cold constitution group was higher? The fact is that the number of warm receptors is lower than the number of cold receptors; thus, sensitivity to warmth is decreased. The number of cold and warm spots on the foot was found to range from 8-23 and 1-6 spots $/ \mathrm{cm}^{2}$, respectively (Lee and Tamura 1995; Tamura and Lee, 1995). The number of cold spots was shown to be 4 to 10 times greater than that of warm spots (Yamauchi and Ayukawa, 2001). The results of these studies indicated that the density of warm receptors is lower than that of cold ones.

Nakayama and Kanosue (1989) reported that cold receptors were closer to the skin surface than warm receptors, with cold receptors $0.18 \mathrm{~mm}$ below the skin surface and warm receptors $0.22 \mathrm{~mm}$ below the surface. Their results were confirmed through an electrophysiological study performed by Nakayama and Kanosue (1989). Hensel et al. (1974) also showed that cold receptors were closer to the skin surface than warm receptors. Green and Cruz (1998) reported that finding warm spots was difficult, suggesting that warm spots are distributed sparsely and irregularly.

The preceding studies consider that the human is generally more sensitive to cold than to warmth. But from our experiments we could not determine why only the warm sensation threshold was high in the cold constitution group although there was no difference in the number of warm spots among the groups.

Since the central nervous system is affected by uncomfortable thermal stimulation, the mechanisms of interaction between the central and peripheral nervous systems as claimed by Harju (2002) must be verified. Our results showing that the cold constitution group has low sensitivity to warmth suggested a peculiarity in the integrity of the temperature information transmitted from the peripheral to the thermoregulatory center. In the future, further experiments should be done to determine whether the unpleasant sensation of being cold influences the sensation of being warm, which are discriminated by somatic sensations.

\section{Conclusions}

Among the cold constitution, intermediate, and normal groups, no significant differences in temperature existed in the foot skin. The warm sensation threshold was $+6.3 \pm 1.09^{\circ} \mathrm{C}$ (mean $\pm \mathrm{SEM}$ ) for the cold constitution group, $+3.4 \pm 2.10^{\circ} \mathrm{C}$ for the intermediate group and $-0.25 \pm 1.96^{\circ} \mathrm{C}$ for the normal group. The warm sensation threshold in the cold constitution group was statistically higher than that in the normal group. However, no significant differences among three groups in cold sensation threshold were noted. Hence, while the cold sensation threshold for the cold constitution group was comparable to that for the other two groups, the warm sensation threshold for the cold constitution group was higher.

As far as objective information about ambient temperature is concerned, no significant differences existed in the perceptual processing of skin temperature among groups, and no significant differences were noted in the distribution of cold and warm spots, which are sensory spots for cutaneous temperature receptors. From the finding that the cold constitution group had low sensitivity to warmness, it was demonstrated that there is a difference between that group and the other groups in the integrity of temperature information transmitted from the peripheral to the thermoregulatory center.

Acknowledgments We wish to thank the university 
students who were interested in the present study and took time out of their busy academic schedules to participate. The study was partly supported by grant-in-aid \#11470528 from the Japan Society for the Promotion of Science.

\section{References}

Aomine M, Yamato T (2002) Characteristic of the electrocardiogram and the clinical features in young women with cold constitution. Jpn J Electro cardiology 22: 10-15 [In Japanese]

Arakawa K, Araki H (1999) A Thermographic Study of the Overaffectiveness by Cold in Young Females-A Simultaneous Cold Water Immersion Test on the Upper and Lower Extremities of the Same Side of the Body. Jap Bull Saitama Prefectural University 1: 23-28 [In Japanese]

Fruhstorfer H, Lindblom U, Schmidt WG (1976) Method for quantitative estimation of thermal thresholds in patients. $\mathrm{J}$ Neurol Neurosurg Psychiatry 39: 1071-1075

Green BG, Cruz A (1998) "Warmth-insensitive fields"evidence of sparse and irregular innervations of human skin by the warmth sense. Somatosens Mot Res 15: 269-275

Harju E (2002) Cold and warmth perception for age, gender, and body area. Somatosen Mot Res 19: 61-75

Hensel H, Andres KH, von During M (1974) Structure and function of cold receptors. Pfluger Archiv 352: 1-10

Horikawa T, Nishiguchi R, Sakaguti T, Tani M, Kawamoto M, Fujikawa O, Yamada H, Noguchi E (1993) Examination of foot rear skin Temperature pattern of Coldness patients. Jap J Biomedical Thermology 13: 39-40 [In Japanese]

Hosono T (2003) Cooling of occurrence mechanism of greatly the searching of the relation part within the brain by the examination and functional MRI by living body parameters simultaneous measuring. J Acta Obst Gynaec Jpn 55: 281 (S-263) [In Japanese]

Iriki M (2003) Body temperature physiology. Bunkodoh, Tokyo, 145 [In Japanese]

Ishino S (1990) Chinese herbal medicine "Coldness". Human Body 199: 101-102 [In Japanese]

Kushima K, Saitoh T (1956) About so-called “Coldness". Jap J Obstetrical and Gynecological Practice 5: 603-608 [In Japanese]

Lee U, Tamura T (1995) Thermal spots over the human body surface (Part 1) Regional difference in cold spot distribution. Jap J Human and Living Environment 2: 30-36 [In Japanese]

Matsumoto S (2001) Coldness and peripheral circulation: Coldness person what differs. Jap J Biomedical Thermology 21: 64-68 [In Japanese]

Matsumoto T, Terasawa M, Takazu M (1990) Difference of Hunting Reaction Toes Between Subjects with and without a Feeling of Cold. Jap J Autonomic System 27: 86-92 [In Japanese]

Nagashima K, Yoda T, Yagishita T, Taniguchi A, Hosono T, Kanosue K (2002) Thermal regulation and comfort during a mild-cold exposure in young Japanese women complaining of usual coldness. J Appl Physiol 92: 1029-1035

Nakayama A, Kanosue K (1989) Thermal Sensation. In Tazaki K, Ogawa T eds. Handbook of physiological sciences, 9, Sensory Physiology. Igaku shyoin, Tokyo, 332-336 [In Japanese]

Nanzandoh (2000) The 18-medicine large dictionary version, Nanzandoh, Tokyo, 53 [In Japanese]

Ohnishi A, Yamamoto T, Murai Y, Ikeda M (1992) CutaneousCooling and -Warming Detection Thresholds in Distal Extremities of Normal Subjects. Jap J UOEH (University of Occupational and Environmental Health) 14: 235-240 [In Japanese]

Physiological Society of Japan (2001) A Guidebook for Student Practicals in Physiology. Nankoudoh, Tokyo, 218-220 [In Japanese]

Sadakata M, Satoh E, Hyodoh K, Sayama M (2003) Characteristics of skin temperature in women with Cold Constitution in a neutral temperature environment. Jap J Maternal Health 44: 193 [In Japanese]

Sadakata M, Sayama M, Minato T, Hyodoh K (2004) Characteristics of peripheral dermovascular in the subjects regarded as the cold constitution. J Jap Society of Nursing Research 27: 106 [In Japanese]

Stevens JC, Choo KK (1998) Temperature sensitivity of the body surface over the life span. Somatosens Mot Res 15: $13-28$

Sugiyama Y, Mano T (1993) The research of the clinical physiology of thermal sensory abnormality. Jap J Gendai Igaku 41: 65-71 [In Japanese]

Takatori A, Okuda A, Sekiba K, Tanizaki K (1990) Thermological Study on Coldness in women. Jap J Environment morbid state study meeting report 61: 46-54 [In Japanese]

Takatori A (1992) Assessment of Diagnostic Criterion of Coldness in Women with Thermography. Acta Obst Gynaec Jpn 44: 559-565 [In Japanese]

Takeya Y (2003) What is it the cooling that I saw medically? Jap J Ayumi of obstetrics and gynecology Chinese medicine research 20: 5-9 [In Japanese]

Tamura T, Lee U (1995) Thermal spots over the human surface (Part 2) Regional difference in warm spot distribution. Jap J Human and Living Environment 2: 37-42 [In Japanese]

Terasawa K (1987) On the recognition and treatment of "Hiesho (Chill phobia)" in traditional kampoh medicine. Article of shoyakugaku 41: 85-96 [In Japanese]

Tsunoda N, Tanaka K, Ohira K, Yamamura T (2005) The Influence of the change in the temperature of the sole upon the somatic receptor and the cognitive in the sole. Proc Phys Ther 32 (Supp1.2): 231 [In Japanese]

Watanabe Y, Suzuki K (1997) Attempt of the objective evaluation of Coldness (the 1st report). Jap K Kampoo Medicine 48: 108 [In Japanese]

Webb P (1992) Temperature of skin, subcutaneous tissue, muscle and core in resting men in cold, comfortable and hot 
conditions. Eur J Appl Physiol 64: 471-476

Yamauchi A, Ayukawa T (2001) The Atlas of Human Sense. Kodansha, Tokyo, 93 [In Japanese]

Received: October 20, 2006

Accepted: April 25, 2007
Correspondence to: Mieko Sadakata, School of Health Sciences Faculty of Medicine Niigata University, 2-746 Asahimachi-dori, Niigata, Niigata 951-8518, Japan

Phone: +81-25-227-2369

Fax: +81-25-227-2369

e-mail: atom@clg.niigata-u.ac.jp 